\title{
A legitimação da Hermenêutica Fenomenológica de Paul Ricoeur
}

\section{Paul Ricoeur's Phenomenological Hermeneutic Legitimation}

\author{
Profa. Dra. Rita de Cássia Oliveira \\ rcoliveira30@yahoo.com.br \\ Universidade Federal do Maranhão
}

Neste artigo, discuto as reflexões de Paul Ricoeur (1913-2005) sobre o processo de legitimação da constitutiva narrativa da linguagem humana em seu aspecto, como diz o filósofo, de linguagem plena, ou seja, dos símbolos, das metáforas e dos mitos. Tal linguagem é a linguagem poética. Nas experiências filosóficas, sobretudo, nos textos de Ricoeur, há esforços de reflexão centrados na linguagem nos quais se desenvolve uma teoria da interpretação em que o discurso é seu ponto de partida e o excesso de sentido é seu horizonte de análise. Portanto, trata-se aqui de pensar a linguagem segundo uma relação entre hermenêutica e poética, já que a reflexão sobre a linguagem, para esse autor, é essencialmente conexa a uma teoria filosófica da interpretação e a sua prática narrativa. Assim, pretendo configurar, nas suas linhas estruturantes, o tema da Hermenêutica Fenomenológica de Ricoeur.
\end{abstract}

\section{PALAVRAS-CHAVE}

Linguagem; Hermenêutica fenomenológica;

Interpretação; Símbolos; Mímesis

In this article, I discuss Paul Ricoeur's (1913 - 2005) reflections about the process of constitutive legitimation of narrative on human language in its aspect, as the philosopher says, full language, i.e., symbols, metaphors and myths. Such language is the poetic language. In philosophical experiments, above all in Ricoeur's writings, there are efforts of reflection centered on the language in which develops a theory of interpretation where in the speech is its own base and meaning excess is its own analysis horizon. Therefore, manage in this way to think the language according to a relationship between hermeneutics and poetic, since the reflection on language, to this author, is essentially related to a philosophical theory of interpretation and its narrative practice. Thus, I intend to set up, in its structuring lines, Ricoeur's hermeneutic phenomenological topic. 
Ricoeur pensa a interpretação da linguagem segundo uma hermenêutica fenomenológica que considera a elucidação da linguagem como extensiva para além dos significados dos símbolos, por buscar a compreensão de novos objetos: o texto, a metáfora, a narrativa, a ação, a história, o imaginário social e a política. Ricoeur desenvolve assim uma possibilidade de interpretação da nossa pertença ao mundo mediada pela linguagem que apresenta uma realidade constituída simbolicamente na plurivocidade; e entre nós e o mundo, entre nós e nós mesmos.

A compreensão da realidade por meio da linguagem exige uma qualidade interpretativa dos seus símbolos e signos que permita o reconhecimento da nossa pertença ao mundo, a uma cultura e a uma tradição. Daí, ser a semântica do "mostradoescondido", das expressões de duplo sentido, o elemento que possibilita à hermenêutica elucidar os vários aspectos textuais que dão acesso à compreensão da existência, da consciência de si-mesmo e da alteridade. Esta é a "via longa" que caracteriza a hermenêutica de Ricoeur por tornar possível a articulação da verdade entendida como desvelamento numa ontologia da compreensão, com os métodos de uma epistemologia da interpretação pregoados pelas ciências humanas. Ricoeur identifica uma limitação da hermenêutica heideggeriana na exposição da pré-compreensão em termos ontológicos. A fundação da hermenêutica fenomenológica que faz aparecer o Ser como condição do compreender é, segundo Ricoeur, sem dúvida, revolucionária, por fazer a inflexão de uma abordagem epistemológica para uma abordagem ontológica pelo deslocamento do problema da consciência histórica para a compreensão originária. Porém, Ricoeur acusa dois problemas: o primeiro, a hermenêutica de Heidegger ao fazer tal deslocamento não considerou a compreensão histórica como uma forma derivada da compreensão ontológica/originária. O segundo, ressalta que Heidegger não esclarece satisfatoriamente como ocorre a passagem da compreensão do estatuto de um modo de conhecer para um modo de ser. Assim, Ricoeur diz que Heidegger prescinde da linguagem e desconsidera todas as discussões metodológicas sobre a interpretação correta, restringindo a hermenêutica a uma "via curta" em que o compreender é mais do que um modo de conhecer e, sim, um modo de ser: "o problema hermenêutico torna-se uma província da Analítica desse ser, o Dasein, aquele que existe ao compreender" (RICOEUR, 1988, p. 8).

A teoria da linguagem em Paul Ricoeur tem como horizonte de análise o excesso de sentido, o que evidencia a referencialidade da "linguagem plena" que seus escritos dos anos 70 e 80, notadamente, La Métaphore Vive e Temps et Récit, procuram constituir e legitimar no horizonte da inovação semântica. Para determinar melhor o problema que aqui coloco, faz-se necessária a expli- 
citação, ainda que sumária, das diferenças entre esses dois domínios de articulação: filosofia e poética. A filosofia, para Ricoeur, parte da tentativa de elucidar o sentido da existência. Por isso, o seu problema filosófico são a extração e a interpretação do sentido. Mas, não é o erro ou a mentira que se revela como questão essencial, e sim, a ilusão, porque se torna urgente que seja desmistificado e restaurado o sentido da linguagem para que seja redescoberta a sua autenticidade. É, então, a filosofia hermenêutica o conhecimento pretendido como capaz de elucidar as múltiplas funções do significar humano, o meio de extrair seu verdadeiro sentido.

No livro Do texto à ação, Ricoeur diz que a tarefa de uma filosofia da hermenêutica é fornecer um conjunto de critérios que mostrem como os métodos de interpretação opostos partem do mesmo lugar, ou seja, da sobredeterminação ou riqueza infinita dos símbolos e que, todos eles são relativos à estrutura teórica da leitura de um texto considerado. O filósofo diz que a hermenêutica perfaz o arco reconstruindo o duplo trabalho de construção de um texto: no nível da sua dinâmica interna, isto é, na sua estrutura possibilitando um sentido e, ainda, no nível do poder que tem para se projetar fora de si mesmo, gerando um mundo: a sua referência. $\mathrm{O}$ círculo hermenêutico estabelecido entre o sentido e a referência torna-se possível porque a compreensão é concebida como uma "arte da conjectura" em relação ao significado do texto.

Já, a poesia, em Ricoeur, é o meio de restituição do poder criador simbólico da vontade humana. Para atingir mais diretamente o essencial da questão da vontade, o filósofo destaca os temas religiosos da "falta" e da "transcendência", fazendo com que haja uma suspensão do juízo sobre os dogmas religiosos do pecado original e das relações do homem para com Deus, fazendo emergir a "falibilidade" empírica da vontade humana, que se revela em toda a sua autenticidade simbólica na poesia trágica. Isso porque é mediante a tragédia que as ações humanas são representadas segundo uma composição que diz a verdade através da ficção, do muthos, libertando a vontade humana por meio da catarsis.

Ricoeur trata especificamente da poesia na obra La Métaphore Vive, como sendo esta uma possibilidade de projeção do mundo em sua dimensão ontológica, um "ser-como". A poesia tem um poder de referencialidade direta ao ser em decorrência de sua estrutura dialética resultante da equivalência subsumida pelo verbo ser em posição metafórica entre o "ver-como" da metáfora e o "ser-como" da própria realidade. Mas, a discussão sobre a poesia em Ricoeur é oriunda da sua investigação sobre a metáfora que, por ter dupla função: retórica e poética, que exige que se adentre na poesia para que ocorra a sua compreensão. 
A exigência hermenêutica da metáfora está no centro da obra La Métaphore Vive, em que Ricoeur historiciza a metáfora desde Aristóteles, passando pelos retóricos medievais, até a sua consideração pelos linguistas modernos. A teoria da metáfora é fundamental para que se compreenda o elo entre hermenêutica e literatura, porque Ricoeur pensa a metáfora enquanto mímesis que origina a criação do muthos, ou seja, da ordenação da intriga. Daí, ser a metáfora uma figura de linguagem insólita que cria semelhanças mais do que as encontra ou as exprime, possibilitando a criação da mímesis. Então, Ricoeur parte da concepção aristotélica de mímesis, que se constitui como uma disposição entre começo, meio e fim na composição da unidade e da ordem da ação, isto é, da imitação ou representação da intriga, fazendo com que esta não seja uma simples reduplicação da realidade. A mímesis aristotélica, de acordo com Ricoeur, não pode ser confundida com a imitação no sentido de cópia.

Si la mimêsis comporte une référence initiale au réel, cette référence ne désigne pas autre chose que le règne même de la nature sur toute production. Mais ce mouvement de référence est inséparable de la dimension créatrice. La mimêsis est poiêsis, et réciproquement. (RICOEUR, 1975, p. 56).

Ricoeur parte da ideia de mímesis em Aristóteles para pensar a sua própria concepção de mímesis apresentada no livro Temps et Récit, como a problematização da intriga operada pela racionalidade narrativa, ainda na capacidade originária de criação do muthos como fundante do epos, até a capacidade de composição de uma obra de ficção que, por ser comandada por regras estilísticas, será definida segundo um determinado gênero literário. A intriga, então, tem que ser submetida a um processo de configuração em que, de uma diversidade de acontecimentos numa totalidade temporal extrai-se uma unidade narrativa e uma unidade temporal; ou seja, a intriga caracteriza-se pela estrutura concordante-discordante transformando os acontecimentos em história e remetendo a uma experiência fictícia de tempo projetada pela disjunção-conjunção entre tempo de contar e tempo contado.

É inevitável o aparecimento da aporia do tempo: como pensar conjuntamente o tempo mortal e o tempo da intratemporalidade da ficção? Como passar de uma temporalidade à outra sem interrupção da capacidade de compreensão da 
dialética entre o mundo efetivo e o mundo ficcional? É em Temps et récit ll que Ricoeur desenvolve uma resposta para estas questões, assegurando que a expansão das operações configurativas não condicionam a uma ruptura na relação entre temporalidade e narrativa.

Les transitions d'un temps, à autre servent de guidage por les transfortions d'une situation iniciale en une situation terminale, em quoi consiste toute intriga. L'idée que les transitions homogènes assurent la consistance du texte, tandis que les transitions hétérogènes en assurent la richesse informationnelle, trouve um écho immédiat dans la théorie de la mise em intrigue (RICOEUR,1984, P 137).

Assim, a teoria hermenêutica de Ricoeur para dar conta da tessitura da intriga em toda a sua complexidade de relação entre temporalidade e narrativa tem alargada a abrangência da mímesis a toda criação e interpretação do muthos poético, ou seja, da intriga sustentadora da textualidade à abertura de sentido que este possa exercer no mundo do leitor.

É com esta perspectiva que a mímesis, em Ricoeur, desenvolve-se em três momentos, a saber: mímesis $l$, que trata da prefiguração do campo prático; mímesis $l l$, que estabelece a concordância interna de uma obra frente à discordância episódica e temporal; e mímesis $l l l$, que trata da projeção do mundo ficcional pertencente à narrativa e sua interferência no mundo efetivo. $\mathrm{O}$ arco hermenêutico é perpassado por um dinamismo que assegura à mímesis $l l$, o papel de pivô por fazer a condução do montante à jusante textual, isto é, o ato de ler constitui a operação que lança o leitor no percurso da mímesis $l$ à mímesis $l l l$ através da mímesis $l l$. Portanto, Ricoeur faz conhecer o poder de organização da intriga enquanto núcleo de uma narratologia que condiciona o recontar da temporalidade humana por meio das narrativas ficcionais e históricas.

Assim, a teoria da tríplice mímesis obriga a perceber que ela releva, fundamentalmente, da perspectiva ricoeuriana sobre a linguagem como mediação humana e como sendo o elemento que identifica o humano, porque o reino humano é o reino da linguagem na medida em que é a linguagem "expressão", e expressão de alguém; isto é, a linguagem solicita o dizer porque é o próprio dizer, e que possibilita a temporalização do ser que insurge no presente do dis- 
curso enquanto acontecimento do discurso. Trata-se, pois, de um dito do dizer que se impõe como uma instância discursiva, por ser um ato que alguém articula linguisticamente como uma experiência que deseja partilhar.

Daí, o mérito de Ricoeur em explicitar o princípio hermenêutico da compreensão da linguagem a partir da distinção entre semiótica e semântica. Essa perspectiva leva a encontrar na frase ou enunciado a unidade linguística mínima de referência. É a frase ou enunciado que vai permitir a Ricoeur introduzir a questão da dupla referencialidade da linguagem: a referência ao mundo e ao sujeito que fala a partir do próprio terreno do estruturalismo.

A semântica definida como a ciência da significação das palavras e das mudanças de significação das palavras, tem-se apresentado como semântica estrutural, que se edificou sobre o postulado da homogeneidade de todas as unidades da linguagem, enquanto signos. A semântica moderna, a partir de Ferdinand de Saussure, tornou-se capaz de dar fundamento novo à mesma descrição dos tropos, porque possui um conceito novo de entidade linguística de base, o signo. Para Ricoeur, o monismo semiótico tinha em Saussure os seus limites e diversas contraposições, mas, mesmo assim, radicalizou-se. Sendo, por isso, que a oposição no plano da metáfora entre uma teoria da substituição e uma teoria da interação reflete a oposição fundamental no plano dos postulados de base da linguística entre um monismo semiótico ao qual se detém a semântica da palavra e da frase, e um dualismo do semiótico e do semântico, em que a semântica da frase se edifica sobre os princípios distintos de todas as operações sobre os signos.

A tese central de Ricoeur em Le conflit des interprétations é que opor o signo ao signo é a função semiótica; representar o real pelo signo é a função semântica, mas, a primeira está subordinada à segunda. A primeira é por causa da segunda, ou, se quisermos, é por causa da função significante ou representativa que a linguagem é articulada. É segundo essa distinção fundamental do semiótico e do semântico que vai se realizar a convergência típica de três domínios: o da linguística da frase ou da instância do discurso, o da lógica do sentido e da referência e o da fenomenologia da palavra. É aí que vai se distinguir o método de Ricoeur, que coloca que, sem a mediação do semiótico e do lógico, a filosofia da expressão e da significação nunca poderá transpor o limiar do semântico, que irá condicionar a inteligibilidade de sistemas semióticos e conferir, pela referência, sentido à distinção entre significante e significado. Assim, a frase, enquanto realização efetiva da virtualidade da língua, possibilita a articulação entre estrutura e função ou entre sistema e acontecimento, realizando o quadrilátero discursivo: alguém diz alguma coisa a alguém sobre alguma coisa. Por 
isso a frase além de ser concebida como uma pura unidade semiológica tem de ser vista também como uma unidade semântica.

Ricoeur diz que o problema semântico distingue-se precisamente do problema semiológico no fato de que o signo, constituído pela diferença, é revestido para o universo, por via da referência. Ou seja, ao nível do plano semiótico, o nosso movimento linguístico se dá num sistema de diferenças; quando se desloca o olhar para o plano semântico entra-se na função significante ou representativa da linguagem onde um signo remete para um real.

Por outro lado, é também a questão da frase ou enunciado que se constitui em mediação para a reintrodução da problemática do sujeito. E Ricoeur apropria-se da temática dos pronomes pessoais de Émile Benveniste, no contexto do horizonte fenomenológico, para explicitar a presença da subjetividade na linguagem. Os pronomes pessoais - eu, tu, ele ou ela - são fatos da língua, definindo-se por relação de oposição (eu e tu opõem-se a ele ou ela, como a pessoa à não pessoa e opõem-se entre si como emissor e receptor). Adverte-se que o sentido do "eu" não se esgota nessa listagem de oposições. O "eu", para Ricoeur designa o indivíduo que enuncia a presente instância de discurso contendo a instância linguística "eu".

Porém, o pronome pessoal "eu", por estar disponível na Língua pode ser apropriado por qualquer indivíduo, o que releva a sua característica de signo vazio enquanto pura disponibilidade que só será preenchido quando um determinado indivíduo preencher este signo vazio ao designa-se a si mesmo como "eu”, mediante um discurso que efetivará a virtualidade da Língua. Entretanto, para que Ricoeur possa assegurar a separação entre semiótica e semântica solicitada pela frase, enquanto concebida como unidade linguística mínima, terá que não aceitar o "eu" como simples criação da linguagem, mas como sendo a capacidade do locutor de se pos cionar como sujeito e de se opor a outrem como interlocutor, sendo o pressuposto extra-linguístico do pronome pessoal. Desde modo, Ricoeur afasta-se de Benveniste para conceber a linguagem como mediação e como meio no qual e pelo qual o sujeito se põe e o mundo se mostra. Afasta-se ainda do estruturalismo ao conceber a significação nos âmbitos dos visados intencionais de uma subjetividade.

Benveniste sublinha que qualquer discurso se produz como um acontecimento por se caracterizar em atos discretos e a cada vez únicos pelos quais a língua se atualiza em falas por um locutor, por isso a expressão "instância do discurso", forjada pelo linguista, para opor o discurso à língua, devido esta ter na sucessão do tempo somente uma existência virtual, na medida em que ela 
existe propriamente quando um locutor dela se apropria e a atualiza. E o discurso, que como acontecimento é transitório e fugaz, como fica a sua existência?

A essa questão, Benveniste responde que o discurso pode ser identificado e reidentificado, através da expressão "mesmo" que introduz à sua significação uma identificação de unidade de discurso, por impor-lhe um sentido. Portanto, a instância do discurso é um acontecimento repetível. Além do mais, o discurso apresenta uma polaridade típica: função identificante e função predicativa: a primeira se caracteriza pelo enlaço do nome e do verbo para formar o logos articulado. Por causa desse entrelaçamento, o discurso visa a alguma coisa e pode ser apreciado, enquanto verdadeiro ou falso. Essa polaridade do identificante e da função predicativa se apresenta, por um lado, nos individuais denominados como seres que existem, mesmo que essa existência seja neutralizada, como é o caso da ficção: sempre se fala de qualquer coisa que é, porque a noção de existência está ligada à função singularizante da linguagem, ora, os sujeitos logicamente próprios são em potencial existentes, daí a "aderência" da linguagem às coisas. Por outro lado, na predicação de qualidade, temos as classes, relações e ações que são, de fato, universais que se referem a objetos empiricamente inexistentes. Então, não faz sentido perguntar se a felicidade existe, mas se um tal que é feliz, existe.

Com efeito, a hermenêutica de Ricoeur reveste-se de uma fenomenologia e passa a considerar três teses sobre a significação: 1 - a significação ser a categoria mais englobante da descrição fenomenológica; 2 - ser o sujeito que transporta ou sustenta a significação; 3 - a redução ser o ato filosófico fundador da emergência de um ser como significação. Ricoeur ainda acrescenta que essas três teses se estruturam de modo a poderem ser percorridas nos dois sentidos: da primeira para a terceira e vice-versa. Da primeira tese para a terceira se tem a ordem da descoberta ou da constituição da posição fenomenológica. Já da terceira tese para a primeira corresponde à ordem da fundação. Daí, o filósofo dizer que é por meio da redução que aparece a nossa relação ao mundo; é na redução e por ela que todo o ser emerge na descrição como fenômeno, como aparecer, portanto, como significação a explicitar e ainda acrescenta que a significação é a mediação universal entre o sujeito e o mundo. A perspectiva fenomenológica de Ricoeur diferencia-se da tradicional naquilo que faz a redução fenomenológica passar pela mediação dos signos, não se articulando tão somente nos termos da dicotomia entre consciência e mundo. Para tanto, busca na linguística e na semântica os meios de compreensão da função simbolizadora da linguagem, a qual se revela como sendo a origem e não uma consequência da vida social.

A linguagem, mais do que descrever a realidade, revela-a e cria-a por meio da narratividade. E a narratividade apresenta-se como o aspecto da linguagem que 
revela o seu sentido autônomo na medida em que lhe confere a condição temporal humana, enquanto capaz de orientar o sujeito em direção à interpretação de sua condição efetiva de ser no mundo, por exigir o ato de recontar. Ricoeur elabora uma teoria da narratividade em Temps et récit, como uma correlação de base ao arcabouço de sua filosofia hermenêutica.

A narrativa é compreendida como o emprego da linguagem que pressupõe uma "unidade funcional" à organização narrativa da experiência humana, que em sua natureza é fragmentada e dispersa. Esta "unidade funcional" que ordena o recontar da experiência humana é o tempo. O filósofo encontra-se em um estágio de conhecimento social em que se atesta a certeza da impossibilidade de expressão da experiência temporal pelo discurso descritivo de tipo científico, quer pela física, biologia, sociologia ou psicologia. A especulação cosmológica empreendida por filósofos como Kant, A crítica da razão pura, por Husserl, em Ideias para uma fenomenologia pura e para uma filosofia fenomenológica, e, Heidegger, em Ser e Tempo, também não consegue apreender tal experiência.

E Ricoeur volta-se para a linguagem indireta, a empregada pela literatura, como sendo a linguagem capaz de mediação do fenômeno do tempo, porque a experiência filosófica de especular o tempo se apresenta como insatisfatória na medida em que o tempo apresenta uma dupla natureza: exterior (física) e interior (vivida). O tempo físico pode ser medido pelo mostrador do relógio, porém, o tempo que aparece na memória ou na imaginação jamais poderá ser mensurado. Além de que a semiótica já comprovou que não há relações necessárias entre as leis internas do discurso com a temporalidade. O tempo só pode ser compreendido como um elemento estrutural do texto. Entretanto, Ricoeur tem que se ater a uma noção de tempo para desenvolver a sua teoria da narratividade e poder compreender como a literatura apreende o fenômeno da temporalidade.

Ricoeur analisa a investigação de Agostinho sobre o tempo, atendo-se à interrogação que o filósofo medieval levantou: “o que é o tempo?”, e percebe que em Agostinho o tempo é mais um enigma onde a linguagem não consegue explicar o "ser" do tempo. O tempo é impossibilitado de ser dito, falado, entretanto, não é impossibilitado de ser compreendido. Como solução para o paradoxo do ser e do não-ser do tempo, Agostinho elaborou a noção de tempo como distensão da alma, porque o não-ser do tempo remete ao argumento cético de que o tempo não tem ser na medida em que o futuro não é ainda, o passado não é mais e o presente não permanece. Sendo assim, como o tempo pode ser? É gerado, pela inscrição do como, um novo paradoxo: a medida. Como medir aquilo que não é? Diante de tais aporias, Agostinho dispõe da ideia de um pre- 
sente único, o qual é caracterizado como o que não mais permanece, e ainda, como o que não tem extensão.

Ricoeur diz que Agostinho submeteu o presente a uma espécie de afinamento para reduzi-lo a um instante pontual como meio de negar a sua extensão. Entretanto, esta é tão-somente uma etapa do método aporético agostiniano, conforme se percebe no dizer de Agostinho:

Todavia, Senhor, nós destacamos os intervalos do tempo e, comparando-os conjuntamente, nós dizemos que uns são mais longos e que outros são mais curtos. Nós sabemos, assim, medir de quanto um tempo é mais longo ou mais curto que outro. (AGOSTINHO, LIVRO Xl, 1987, p. 219).

A partir daí, a noção de presente como instante pontual é substituída pela noção de passagem, de transitoriedade: "quando, então, o tempo passa, podemos percebê-lo e medi-lo" (AGOSTINHO, LIVRO Xl, 1987, p. 220). O paradoxo da medida do tempo fica esclarecido quando Agostinho ressalta que é apenas o passado e o futuro que se pode constatar como sendo longo ou breve, porque do passado se diz que se alonga e do futuro que se encurta. O passado se reconta $\mathrm{e}$ o futuro se prediz. Ricoeur observa que Agostinho admite os termos passado e futuro como adjetivos por serem qualidades temporais do presente.

A partir daí, a noção de presente como instante pontual é substituída pela noção de passagem, de transitoriedade: "quando, então, o tempo passa, podemos percebê-lo e medi-lo" (AGOSTINHO, LIVRO Xl, 1987, p. 220). O paradoxo da medida do tempo fica esclarecido quando Agostinho ressalta que é apenas o passado e o futuro que se pode constatar como sendo longo ou breve, porque do passado se diz que se alonga e do futuro que se encurta. O passado se reconta e o futuro se prediz. Ricoeur observa que Agostinho admite os termos passado e futuro como adjetivos por serem qualidades temporais do presente.

Ricoeur diz que se trata de um outro presente: "ele também se tornou adjetivo plural (praesentia), alinhado com praeterita e futura". E a multiplicidade da alma permite alojar o paradoxo do ser e do não-ser do tempo no plano subjetivo, de tal modo que são colocadas as condições para a resolução do enigma do tempo de um "ser que falta ser", ou seja, um ser que não é mais (passado), não é sempre (presente), não é ainda (futuro). O tempo é presente: presente do passado, presente do presente e presente do futuro. O tempo é tríplice presente. 
Ricoeur se atém à indagação sobre o lugar, o onde, da alma em que se alojam as coisas do passado e que possibilita o seu recontar, porque é exatamente no âmbito dessa problemática que se encontra implicada as noções de narração e previsão. Com efeito, é dentro da alma, mais exatamente na memória, que estão registradas como rastros as coisas que foram vividas no passado. Ricoeur diz que quando se reconta coisas verdadeiras, embora sejam coisas passadas, é da memória que são tiradas; não são as coisas, elas mesmas, que passaram, mas as palavras concebidas a partir das imagens que estão gravadas no espírito, como marcas que passaram pelos sentidos.

A previsão se torna possível devido a uma expectativa presente, a uma espera que fazem as coisas futuras advirem como presentes. Assim, a expectativa precede o acontecimento que não é ainda, consistindo numa imagem que passa a existir no presente, mesmo não sendo uma marca deixada pelas coisas passadas. A previsão é uma pré-percepção que nos permite anunciá-la mesmo ainda não sendo, porque é um signo e uma causa do futuro. Ricoeur considera a solução de Agostinho, de ser a memória a destinação das coisas passadas e futuras, como perspicaz para o seu empreendimento de explicitação do tempo como "unidade funcional" da racionalidade narrativa.

A teoria do tríplice presente de Agostinho sustenta a ideia da distensão da alma e permite a espera, faz a atenção e se lembra. Assim, ocorre uma relação entre a atividade e a passividade segundo uma interação entre a espera, a memória e a atenção desencadeando uma ação que torna breve a expectativa e alonga a memória. Ricoeur conclui, então, que a atividade e a passividade são funções do espírito que se contrariam; havendo ainda uma discordância entre as duas passividades pelo fato de uma está vinculada à expectativa e a outra à memória. Portanto, o que constitui a temporalidade é uma contínua discordância no interior do tríplice presente. Ricoeur visa essa estrutura de discordância-concordância como sustentadora à sua investigação sobre a correlação entre o tempo e a tessitura da intriga como origem do discurso narrativo.

É essa estrutura concordante-discordante da temporalidade articulada com a estrutura concordante-discordante da intriga que possibilita que a mímesis da ação seja a expressão da racionalidade narrativa, sob a forma de discurso narrativo. O processo de passar da atividade da ação para a atividade de construção de um texto exige as funções de integração e de mediação, em que predomina três momentos: o primeiro se caracteriza pelo encadeamento de uma simples sucessão a uma configuração a partir da ordenação de uma multiplicidade de ações ou acidentes individuais sob a forma de uma intriga, que tem como de- 
senlace a explicitação dos motivos que explicam por que alguém faz ou deixou de fazer uma algo. E, daí, a ação ter como resultado uma mudança de sorte em direção à felicidade ou ao infortúnio.

Em segundo lugar, os elementos heterogêneos, tais como agentes, fins, meios, circunstâncias, cooperação, conflitos, etc., são compostos em uma configuração concordante. E em terceiro lugar, ocorre uma combinação das proporções variadas de uma dimensão de tempo cronológica com uma dimensão de tempo não cronológica. Estando mediados os caracteres temporais, a organização da intriga engendra uma representação de tempo que obedece à ordem cronológica de um após o outro e uma representação de tempo não cronológico com um encadeamento configurativo, um por causa do outro. O tempo tem direções postas nestas duas representações, porém, ambas são apreendidas pelo leitor.

Dessa forma, a narração tem o seu desenvolvimento dentro do tempo. Essa condição torna-se explícita quando Ricoeur faz a correlação entre as noções de distentio animi e muthos, pois estes conceitos tomados separadamente não explicariam a sua tese de que o tempo se torna tempo humano quando articulado pela narrativa. Ora, o tempo pelo qual trata a Poética de Aristóteles concerne a um tempo interno da obra, aquele dado pela noção que o leitor faz do todo da obra. E a especulação de Agostinho sobre o tempo além de possibilitar a compreensão do tempo humano como tempo narrativo, integra-se as indagações de Ricoeur sobre a morte e a eternidade. É, com efeito, nesse ponto de interseção entre esses dois conceitos tão distantes, que se encontra a novidade da teoria ricoeuriana.

É, ainda, neste ponto de interseção entre os conceitos de distentio animi e muthos que a tessitura da intriga será configurada de tal forma que consistirá na consideração da multiplicidade dos acontecimentos tornando-se apta a ser seguida pelo leitor que ao concluir o conjunto da história construída pelo poeta, será orientado para os fatos que ocorreram no início dando-se, então, a sua intelecção como um todo. Com efeito, a intriga constitui-se em uma síntese da heterogeneidade porque organiza uma unidade de sentido, ou seja, uma história, a partir da ordenação de uma multiplicidade de elementos diversos, ocorrendo uma oposição entre o mundo inventado pelo poeta, o mundo do como se, e o mundo onde se desenvolve a ação efetiva, o mundo real.

A intriga introduz uma ruptura entre o mundo fictício e o mundo real, porém, essa cisão não impossibilita que a arte poética permaneça vinculada à ação efetiva. Ricoeur observa que este vínculo faz com que o modelo aristotélico seja paradoxal na medida em que mesmo inserindo o corte com o mundo real, mantém uma ligação oblíqua, indireta com a dimensão da ação. Portanto, o termo 
ficção se reveste de dupla significação: uma geral, como sinônimo de configuração imaginada - em epopeias, dramas, romances, tragédias, novelas - e outra particular, que contraria a pretensão da narração histórica convertendo-se em narrativa verdadeira, uma vez que este gênero de discurso se pauta nas ações que de fato ocorreram. Essa delimitação do significado de ficção conduz a uma bifurcação no sentido de narração em: narrativa de ficção e narrativa histórica.

O conhecimento historiográfico deriva, assim, das operações de configuração características da intriga. Esta tese é defendida por Ricoeur na segunda parte de Temps et récit $l$, onde assevera o não rompimento do vínculo de base da competência humana de seguir uma história com a condição do estatuto de cientificidade conferido ao conhecimento histórico. Isso porque, quando o conhecimento histórico reconstrói um fato que foi real no passado, os procedimentos utilizados são da mesma ordem do engendrar de uma intriga e, do leitor, são exigidos os mesmos recursos cognoscitivos específicos da compreensão narrativa.

Mas, a historiografia pertence ao campo narrativo de modo indireto e não mediante um elo progressivo, uma vez que Ricoeur confronta a estrutura concordante-discordante da intriga com os modelos que fundam a metodologia científica com o objetivo de responder as questões que emergem com o problema do vínculo entre explicação histórica e compreensão narrativa, o que faz com que ele se depare com a dicotomia entre história e narrativa de ficção. Ou seja, mesmo tendo ambas a mesma base: os mecanismos de ordenação da intriga, isso não significa que têm um desenvolvimento comum. No entanto, Ricoeur se certifica de que o mundo da ação é tomado continuamente em consideração, tanto para o prévio plano cultural de onde o poeta cria o mundo ficcional, como para o plano científico em que o historiador reconstrói a ação histórica.

Entretanto, mesmo diferenciando-se em métodos e perspectivas, ficção e história se cruzam mutuamente na categoria prática da Identidade Narrativa, como a chama Ricoeur, dizendo que esta é um rejeton, isto é, um produto simultaneamente concebido como solução e problema, resultante "de uma longa viagem através da narrativa histórica e da narrativa de ficção" (RICOEUR, 1988, p. 295), que Temps et récit consolida. A categoria identidade narrativa aparece no final de Temps et récit $1 l l$ como resultante da articulação entre história e ficção segundo a concepção da História e da Ficção Literária terem uma natureza epistemológica que consiste em: por um lado, que o fazer história necessita da narrativa pelo fato de ser o passado irrecuperável e, por isso a imaginação ser invocada como recurso para a sua análise, aproximando a história da ficção; por outro lado, o reconhecimento que a criação ficcional, enquanto resultante de um uso poético da 
linguagem, é dotada de uma capacidade de referência ontológica intrínseca, o que viabiliza a criação de histórias que originam mundos verossímeis e habitáveis.

A identidade narrativa emerge como uma relação hermenêutica inexpugnável que ata narratividade e temporalidade, porque enquanto rejeton é o princípio de solução da primeira aporia da temporalidade: a de ser possível a ligação entre o tempo cosmológico com o tempo fenomenológico. Como categoria prática, a identidade narrativa é o modelo de resposta a essa interrogação possível: quem é o responsável por esta ação? Ou, quem é o seu agente? Ela se insere na questão ricoeuriana do Cogito ferido ou fragmentado, em articulação com a temática da identidade pessoal que será desenvolvida em Soi-même comme un Autre (1990), em que Ricoeur se ocupa com a questão do Cogito mediante o desdobramento do tema da responsabilidade humana ou de sua capacidade de iniciativa em quatro enunciados diretores: posso falar, posso agir, posso narrar e narrar-me e posso ser imputável, dando origem a quatro áreas de análise no plano do agir do sujeito, subsumidas na intercepção de três jogos de linguagem: descrever, narrar e prescrever. A modalidade narrativa da ação, pela posição que ocupa, torna possível uma interpretação da identidade pessoal pela mediação entre o plano do agir descritivo e o plano da promessa, prescritivo, fazendo aparecer a discussão sobre a ética e a moral com imprescindível para uma filosofia que acredita ser a literatura um fecundo "laboratório de experiências imaginativas".

ADORNO, Theodor W. Notas de literatura I. Tradução Jorge de Almeida. São Paulo: Duas Cidades/34, 2003.

AGOSTINHO, Santo. As confissões. Os pesadores. São Paulo: Abril Cultural, 1987.

AMALRIC, Jean-luc. Ricoeur, Derrida. L'enjeu de la métaphore. Philosophies. Paris: Presses Universaires de France, 2006.

ARISTÓTELES. Poética. Tradução Eudoro de Souza. São Paulo: Nova Cultural. 1987.

AUERBACH, Erich. Mimesis. Tradução de Vários. São Paulo: Perspectiva, 2004.
BENVENISTE, Emile. Problemas de Linguística Geral l. 3 edição. São Paulo: Pontes, 2003.

CASTRO, Maria Gabriela Azevedo. Imaginação em Paul Ricoeur. Lisboa: Instituto Piaget, 2002.

CESAR, Constança Marcondes (org.). Hermenêutica francesa: Paul Ricoeur. Porto Alegre: EDIPUCRS, 2002. Paul Ricoeur: ensaios. São Paulo: Paulus, 1998. GAGNEBIN, Jeanne Marie. Uma filosofia do Cogito Ferido: Paul Ricoeur. Etudos avançados II (30), 1997.

WAHL, François. Estruturalismo e filosofia. Tradução Alfredo Bosi. São Paulo: Cultrix, 1973. 
HENRIQUES, Fernanda (org.). A filosofia de Paul Ricoeur.

Coimbra: Ariadne, 2006.

JAKOBSON, Roman. Lingüistica e comunicação. Tradução Izidoro Blikstein; José Paulo Paes. São Paulo: Cultrix, 2001.

KANT, Immanuel. Crítica da razão pura. Tradução Manuela Pinto dos Santos; Alexandre Fradique Morujão. Lisboa: Calouste Gulbenkian, 1985.

LEAL, Ivanhoé Albuquerque. História e ação na teoria da narrativa de Paul Ricoeur. Riode Janeiro: Relume Dumará, 2004.

PIVA, Edgard Antonio. A questão do sujeito em Paul Ricoeur. In: Síntese. Belo Horizonte: v. 26, no 85, 1999.

RICHARDS, I. A. A prática da crítica literária. Tradução Almiro Pisetta; Lenita Maria Rimoli Esteves. São Paulo: Martins Fontes, 1997.

RICOEUR, Paul. Oúnico eo singular. Tradução Maria Leonor F. R. Loureiro. São Paulo: Unesp, Belém: UEPA, 2002.

HAHN, Lewis Edwin (org.). A filosofia de Paul Ricoeur. Lisboa: Instituto Piaget, 1977.

. La mémoire, l'histoire, l'oubli. Paris: Seuil, 2000.

.Lectures 1. autour du politique. Paris: Seuil, 1991.

. Soi-même comme un Autre. Paris: Seuil, 1990.

O conflito das interpretações: ensaios de hermenêutica. Tradução M. F. Sá Correia. PortoPortugal: Rés-Editora, 1988.

.Do texto à acção. Tradução de Alcino Cartaxo

e Maria José Sarabando. Porto-Portugal: RésParis: 1993.

. Temps et récit. III. Paris: Seuil, 1985.

Temps et récit. I. Paris: Seuil, 1983.

Temps et récit. II. Paris: Seuil, 1984.

. La métaphore vive. Paris: Seuil, 1975

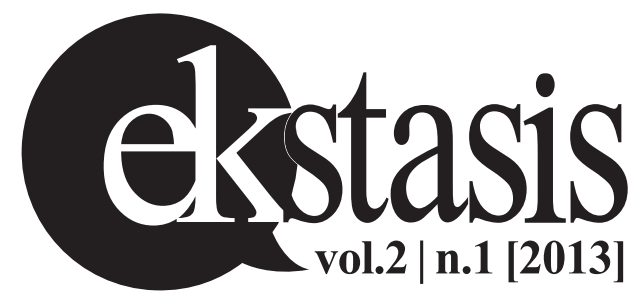

